\title{
WORLD RED CROSS DAY
}

In 1975, the theme for World Red Cross Day, which will be commemorated on 8 May, is to be Red Cross: your emergency lifeline.

In order to prepare for this event which attracts ever greater interest every year, the latest number of the League's newssheet "Panorama" has been issued in a novel form. When the inside pages are unfolded, they constitute a poster highlighting emergency relief action. Today's formula for aid, generosity plus technology, is given in a few sentences: "When you want to help, experience counts. The Red Cross has been answering SOS calls for over a century. The League of Red Cross Societies in Geneva reckons on launching an international appeal for aid to disaster victims once every three weeks on average, year in, year out. The International Committee of the Red Cross stands ready to assist war victims. And in almost every country on the globe volunteers Red Cross, Red Crescent and Red Lion and Sun Societies are dealing with disasters, minor or major, on a daily basis".

National Societies are urged in this way to do all they can in 1975 to bring to people throughout the world additional information on the activities performed by Societies in emergency situations and, thereby, to obtain more extensive support for their humanitarian work. 


\section{PHILIPPINES}

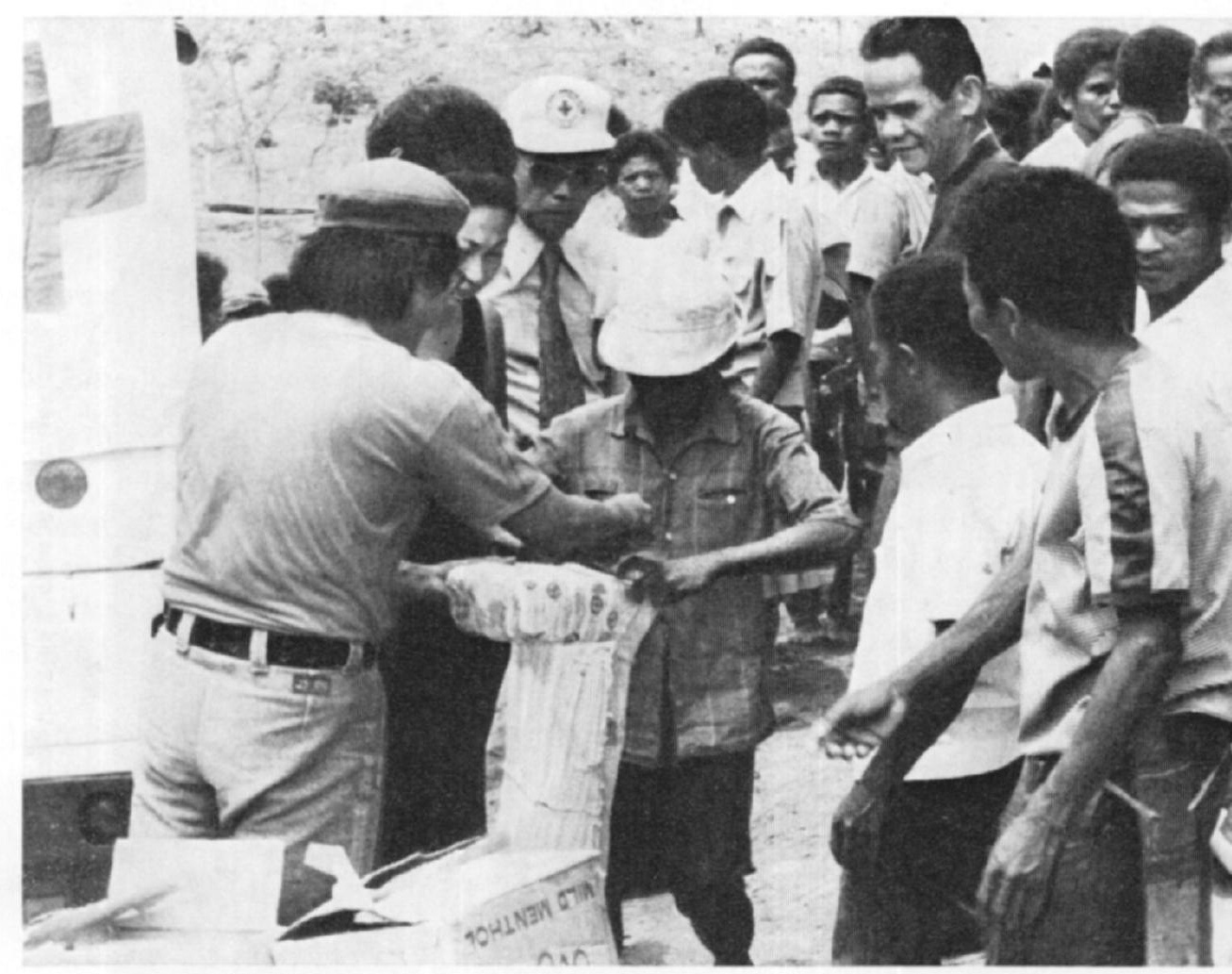

Activities of the Philippine Red Cross for the country's cultural minorities: relief distribution. 


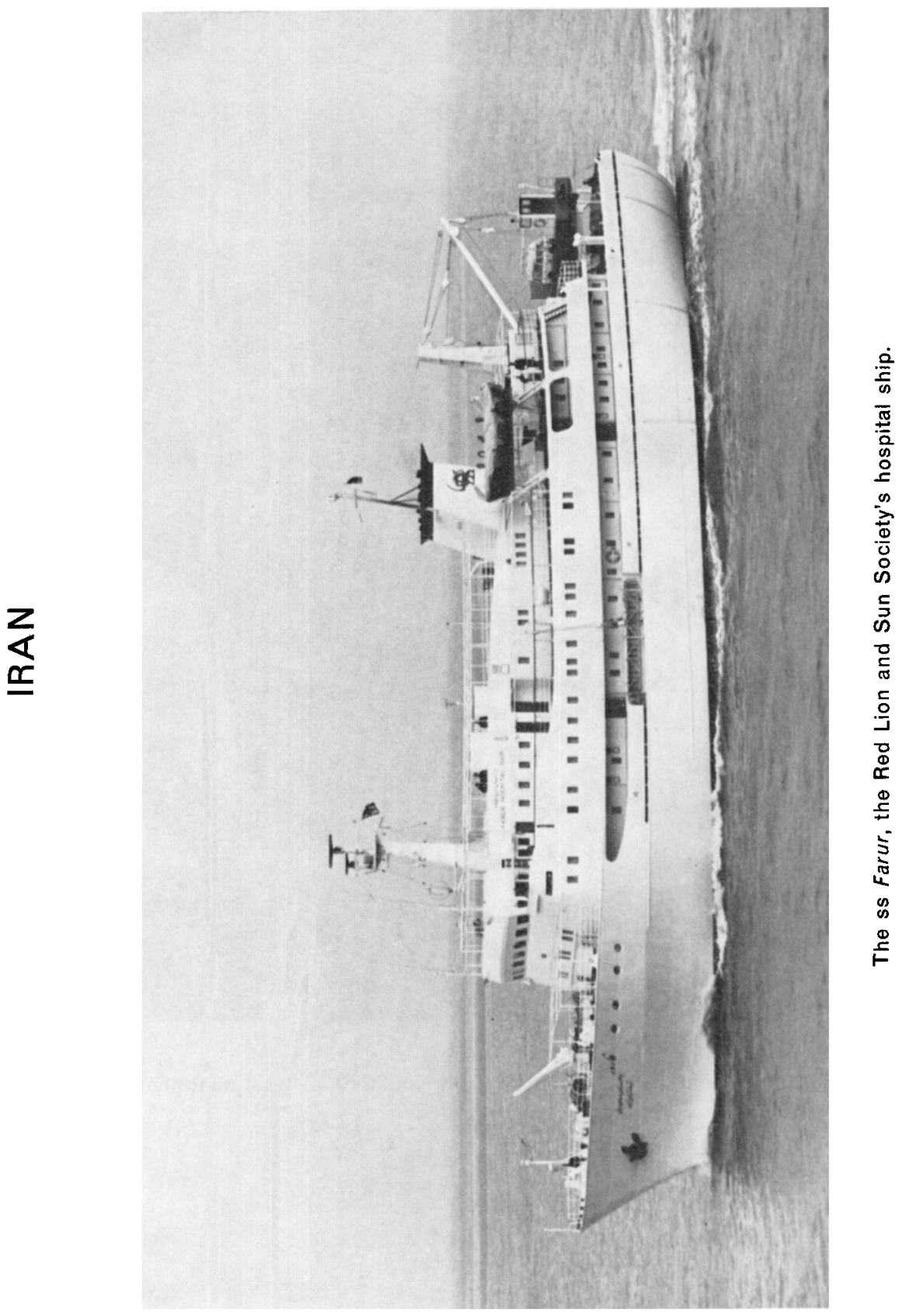

